simple statistical test was made of the reliability of each of the two main effects by applying a sign test (Siegel, 1956) to the number of $S s$ who did and did not show the initial proactive decline. and the relative number of $S s$ who showed the proactive release (i.c., Trial 7 higher than the average of Trials 6 and 8 ). In both cases, the sign test yielded probabilities lower than .05 associated with relevant null hypotheses.

\section{DISCUSSION}

The initial decline in performance over the course of the first six problems of each day is interpreted as the result of the development of proactive interference in short-term memory. The effect is short term in the sense that the interpolated interval of a day between sessions restores performance to its original level. The retentional nature of the finding is suggested in part by the decremental direction of the change. Other (nonretentional) interproblem transfer effects that migh be expected here-learning set or intradimensional shift-are incremental in effect.

Further evidence of the retentional nature of this proactive effect comes from a study by Knight (1968), who showed the temporal control of proaction. Very short intertrial intervals prevent proaction from developing. The conclusion is that the proactive effect is on retention rather than learning.

The increment on Trial 7 is interpreted as a release from proactive interference. To make a formal derivation of this effect, a short-term memory model is needed, such as that of Atkinson \& Shiffrin (1968), with the added assumption of separate buffer

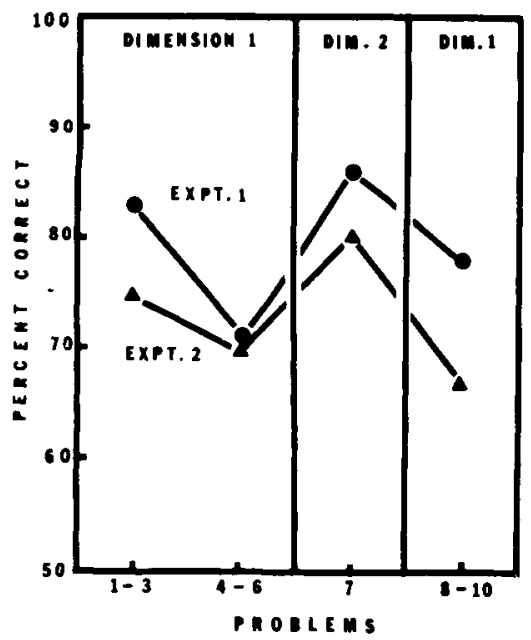

Fig. 1. Mean percentage correct performance on test trials of successive problems. Proaction develops over the first six problems, is released on Problem 7, and returns on the last three problems. storages for the dimensions of color and form. As the short-term storage for one dimension fills up and suffers interference, the other remains relatively empty and free of interference to give rise to the "release" phenomenon.

For a more complete account of the performance of retardates on discrimination problems of the type studied here, there is needed a composite of attention and retention models both of which use the same dimensions of stimuli.

\section{REFERENCES}

ATKINSON, R. C., \& SHIFFRIN, R. M. Human memory: A proposed system and its control processes. In K. W. Spence and J. T. Spence (Eds.). The psychology of learning and motilation. Vol. 2. New York: Academic Press. 1968. Pp. 89-195.

BROADBENT, D. B. Perception and communication. Oxford: Pergamon Press, 1958.

HOUSE, B. J., \& ZEAMAN, D. Miniature experiments in the discrimination learning of retardates. In L. P. Lipsitt and C. C. Spiker (Eds.). Advances in child development and behavior. Vol. 1. New York: Academic Press, 1963. Pp. 313-374.

KVilith II. $S$. The effects of inter-trial interval duration on short-term retention of a twochoice visual discrimination task by retarded children. Inpublished doctoral dissertation. Lniservity of Connecticut. 1968.

LOESS, H. Proactive inhibition in short-term memory. Journal of Verbal Learning \& Verbal Behavior, 1964, 3, 362-368.

SCOTT, K. G. Some parameters of short-term recall. Unpublished $\mathrm{PhD}$ dissertation, University of Connecticut, 1966.
SCOTT, K. G.. \& SCOTT, M. S. Research and theory in short-term memory. In N. R. Ellis (Ld.), International review of research in mental retardation. Vol. 3. New York: Academic Press, 1968. Pp. 135-157.

SHEPP, B. E., \& TURRISI, F. D. Learning and transfer of mediating responses in discrimination learning. In N. R. Ellis (Ed.), International review of research in mental retardation. Vol. 2. New York: Academic Press, 1967. Pp. 82-120.

SIEGEL, S. Nonparametric statistics for the behavioral sciences. New York: McGraw-Hill, 1956.

TURVEY, M. T. Analysis of augmented recall in short-term memory following a shift in connotation. British Joumal of Psychology, 1968, 59, 131-137.

WICKENS, D. D., BORN, D. G., \& ALLEN, C. K. Proactive inhibition and item similarity in short-term memory. Journal of Verbal Learning \& Verbal Behavior, 1963, 2, 440-445.

WOLFF, J. L. Concept-shift and discrimination-reversal learning in humans. Psychological Bulletin, 1967, 68, 369-408.

ZEAMAN, D., \& HOUSE, B. J. The role of attention in retardate discrimination learning. In N. R. Ellis (Ed.), Handbook of mental deficiency. New York: McGraw-Hill, 1963. Pp. 159-223.

\section{NOTE}

1. This research was carried out at the Mansfield State Training School, Mansfield Depot, Connecticut. The investigators wish to express appreciation for the active cooperation of Francis P. Kelley, Superintendent, and Louis Boly, Director of Training. This study was supported by Research Grants M1099 and K6-MH-HD-20,325 from the U.S. Public Health Service.

\title{
The relative effectiveness of positive and negative information feedback in a concept attainment
}

\section{task}

LINDA S. SIEGEL ${ }^{1}$ and JERROLD L. DOWNEY, University of Missouri, Columbia, Mo. 65201

The relative effectiveness of positive and negative verbal feedback was investigated in an attempt to ascertain whether the differential effect was due to reinforcement value of the feedback or to some difference in information gained from the feedback. College Ss solved a concept attainment task under one of two conditions: (1) right-nothing (R-N), feedback for correct responses onlv, or
(2) nothing-wrong (N-W), feedback for incorrect responses only. The expectation that, when the frequency of "right" and "wrong" feedback was controlled, there would be no difference between conditions was not supported, with $N-W \quad S s$ performing significantly better than $R-N$ Ss.

Investigations regarding the relative effectiveness of verbal feedback combinations in concept attainment have led to the suggestion (e.g., Buss \& Buss, 
1956) that "wrong" is a stronger negative reinforcer than "right" is a positive reinforcer. However, in these studies, feedback for incorrect answers occurred more frequently than feedback for correct answers, which led Bourne (1966) to suggest that, rather than ascribing the result to a greater reinforcing value for wrong relative to right, the obtained difference might have been due to the more frequent occurrence of wrong and thus a greater amount of informative feedback presented to $S$ in this condition.

The present study represents an attempt to contrast the relative effectiveness of "wrong" and "right" as reinforcers with the information value of each controlled. Specifically, the hypothesis tested was that when the frequency of "right" or "wrong" was equated for all Ss, there would be no difference between right and wrong feedback conditions.

\section{METHOD}

The Ss were 40 students selected randomly from various psychology classes at Lincoln University. Twenty Ss were assigned to each of two groups: N-W, in which feedback was given only for wrong responses, and $\mathrm{R}-\mathrm{N}$, in which feedback was given only for right responses. The stimuli were geometric forms varying in five binary dimensions: shape-triangle or circle; color-blue or yellow; size-large or small; number-one or two; and striations-absent or present.

All Ss were tested individually. The Ss were instructed about the stimulus dimensions and the requirements of the task. S was asked to state whether each instance was or was not an example of the concept and what his hypothesis was about the concept. The first instance presented to $S$ was an example of the concept, and the remaining stimuli were presented according to the schedules described below.

For both the R-N and N-W groups, a variable ratio schedule of $1: 3$ for feedback was used; that is, $E$ gave $S$ feedback at a mean rate of one out of three responses, regardless of whether the particular instance was positive or negative. In order to achieve this ratio of feedback for all Ss, it was occasionally necessary for $\mathrm{E}$, upon hearing S's hypothesis from the last trial, to manipulate the next presentation in such a manner that the desired correct or incorrect response was forthcoming. For example, if the cancept was striped circles, the condition was R-N, and on the first trial, S said "No" and was incorrect; therefore $E$ said nothing, except to ask $S$ for a hypothesis. On the next trial, $S$ said "Yes," and it was incorrect; then E said nothing, except to ask again for a hypothesis. The situation, at this point, was two trials with no feedback; therefore,
E desired $S$ to be correct on the next trial. $E$ again asked $S$ for his hypothesis. Assume that S said, "I think the concept is yellow circles." $\mathrm{E}$, at this point, checked the next presentation to insure that the forthcoming stimulus was something other than yellow circles and a negative intance of the concept. Presumably S then said, "No, this is not an instance of the concept," and E then said, "Right," since S's response was, in fact, correct. Presentations proceeded in order until such time as manipulation was necessary, when $E$ then chose the card closest to the bottom of the stack of cards that would presumably achieve the desired response from $\mathbf{S}$.

The criterion of learning for all Ss was a correct statement of the concept, which was "large yellow" figures. If the criterion was not reached in 64 trials, the experiment was terminated.

\section{RESULTS AND DISCUSSION}

The mean number of trials required for N.W Ss was 22.4 , which was significantly less $(t=2.63, \mathrm{df}=38, \mathrm{p}<.05)$ than the mean number, 40.4 , required for R-N Ss.

The hypothesis that when the number of trials followed by feedback, or reinforcement, is equated then the R-N and $\mathrm{N}-\mathrm{W}$ conditions will not differ in concept attainment is clearly not supported by the present results. It appears that alternative explanations are necessary in order to account for the superiority of the N-W condition.

It should be noted that in the present experimental design, some Ss, following their hypothesis about what the concept was, proceeded to give answers on the next trial that were not consistent with their hypothesis. When this occurred, it became impossible to maintain the feedback ratio at $1: 3$. Therefore, while the mean feedback ratio in the N-W condition was very close to $1: 3(36 \%)$, the mean feedback ratio in the R-N condition was slightly higher, at $41 \%$.

In consideration of the greater percentage of feedback in the R-N condition and yet the inferior performance, the question might be raised as to whether or not the verbalized "Right" in the R-N condition is always of some positive value in concept formation. If the feedback, "Right," is consistently of value, it would be expected that those Ss whose feedback ratio was higher would attain the correct concept in fewer trials. In an attempt to see if this result was obtained, feedback percentages for Ss in the R-N condition were correlated with the number of trials to criterion. The result, using Spearman's Rho was an insignificant, slightly negative correlation of -.14 . This same correlation in the N-W condition was $.44(\mathrm{t}=2.05, \mathrm{p}<.05$, one-tailed $)$.
It appears, then, that, while N-W Ss did improve their performance with increased feedback, such was not the case with R-N Ss. This lack of effectiveness of "Right" as a reinforcer can perhaps be accounted for, in part, by the fact that there are trials where $S$ is told "Right" when his hypothesis may, in fact, be incorrect. For example, in the R-N condition, if $S$ is shown a negative instance and reports "No," then E states "Right." Obviously, S is afforded no clue that his hypothesis should be altered (except possibly that the experiment did not stop) so that if his hypothesis was incorrect, then being told "Right" may not help. Positive instances, as well as negative, afford the possibility of this contingency.

Apparently, it becomes necessary, in the R-N condition, for $S$ to clearly differentiate between the accuracy of his hypothesis and the accuracy of his response. In other words, $\mathbf{S}$ must listen to the verbalized reinforcement and disassociate it completely from his hypothesis. The data would indicate that it is a difficult differentiation for many Ss, and yet it appears that if it does not occur then the trials described above might actually constitute misinformation. Boume (1966) has recognized the possible ambiguity of "right" as a feedback signal, stating that a correct response could occur by chance without having solved the problem.

It should be noted that this ambiguity of "Right" leads to certain differences in the two conditions. N-W Ss are told directly that their response is incorrect (and, therefore, the hypothesis on which it was based) and presumably they proceed to verbally state an altered hypothesis. On the other hand, R-N Ss are never told directly either that their response or their hypothesis is incorrect. Neither are they verbally stating a new hypothesis immediately following feedback. While the importance of these differences is not clear, they nevertheless exist.

Although it is possible, on the basis of the present experiment, to conclude that the greater frequency of "wrong" signals alone does not account for the superior performance of N-W Ss, it remains to be shown whether the effect is due to "reinforcement," or to a lesser ambiguity of "wrong" signals, or to some other factor.

\section{REFERENCES}

BOURNE, L. E., JR. Human conceptual behavior. Boston: Allyn \& Bacon, 1966.

BUSS, A. H., \& BUSS, E. H. The effect of verbal reinforcement combinations on conceptual leaming. Journal of Experimental Psychology, 1956, 52, 283-287.

NOTE

1. Now at Psychiatry Department, McMaster University, Hamilton, Ont., Canada. 